\title{
Mapping Intergenerational Masculinities on Instagram
}

\author{
Inês Amaral ${ }^{1,2(\otimes)}$, Sofia José Santos ${ }^{3,4}$, and Maria José Brites ${ }^{5}$ \\ ${ }^{1}$ Faculdade de Letras da Universidade de Coimbra, Coimbra, Portugal \\ ines.amaral@uc.pt \\ 2 Centro de Estudos de Comunicação e Sociedade da Universidade do Minho, Braga, Portugal \\ ${ }^{3}$ Faculdade de Economia da Universidade de Coimbra, Coimbra, Portugal \\ sjs@ces.uc.pt \\ ${ }^{4}$ Centro de Estudos Sociais da Universidade de Coimbra, Coimbra, Portugal \\ 5 Universidade Lusófona/CICANT, Porto, Portugal \\ mariajosebrites@ulp.pt
}

\begin{abstract}
Gender identities and roles do not stand alone but rather evolve while intersecting with other traits, namely age, resulting in cross and hybrid (gender and age) identities. Media are one of the pivotal formative spaces where audiences learn role models and the way they should express and behave: Therefore, media environments influence the way one perceives and understands age and gender identities as well as expresses them publicly. Media also promote (inter)generational contexts given that different age groups organize their technological experience in their own specific ways and interact with different other generations. This article explores how masculinities are represented in the digital realm, shedding light on intergenerational dynamics and collective hashtag narratives. Specifically, this article will analyse collective narratives on Instagram through a hashtag stream, focusing specifically on representations of masculinities and how different generations interact and represent how to be, behave and express as "a man".
\end{abstract}

Keywords: Generations · Ageing $\cdot$ Masculinities $\cdot$ Gender identities $\cdot$ Collective narratives

\section{Introduction}

As gender is a social construction, gender identities and roles are not immanent nor immutable [1]. Masculinities and femininities represent, thus, culturally and socially constructed ideals of what a boy/man and a girl/woman should be, express themselves and behave. These have been built within patriarchy and on a relational and binary basis $[2,3]$. Although there is a prevailing conception of what it means to be a boy/man and a girl/woman, femininities and masculinities are multiple (depending on context, ideology, experiences, and sense of self) and, at times, even contradictory [2, 4]. As an identitarian element, gender identities and roles do not stand alone but evolve while intersecting with other traits or social categories, such as class, race and age. In point of 
fact, the expression of gender identities is also anchored upon a generational sense of belonging. To be an "old man" (as hegemonically conceived, see Sect. 1.1) might entail features "young adults" are not allowed to have. According to Mannheim [5], there is a continuing character of generational changes that broadens the notion of a 'generational situation'. In the same line of reasoning, Corsten proposes the notion of a "we sense" [6] in order to summarize historical and social experiences that are lived individually or collectively, enabling the identification of subjects with various generational groups.

The media are one of the key formative spaces where boys and girls, and men and women learn how to be, express themselves, and behave in terms of gender identities [8]. Likewise, media environments can emerge as (inter)generational contexts given that different age groups organize their technological experience in their own specific ways. In fact, media experiences take place within people's cultural environments [9], an idea that is associated with belonging to a group. Historical and social experiences refer to the concept of 'we-sense' [6] and allow the identification of a specific subject with particular groups. Images contribute substantially to the creation of the we-sense, as people can have a concrete sense of specific experiences even if they existed before they were born, thus serving as a memory of unlived narratives, or happened elsewhere, thus creating expectations or fears.

If this mass media power concerning the formation of identities has been rendered consensual $[3,6,7]$, the digital realm has not been an exception. Similar life experiences and cultural backgrounds induce identical appropriations of digital media, which, in turn, might generate the notion of a generational identity [5]. It follows that the different generations experience a social and technological change in an intergenerational logic. Social media allows the sharing of images that build intergenerational narratives. In computer-mediated communication platforms, connectivity patterns exist that metamorphose digital culture, enabling the identification of content-based social networks and conversation-based social networks. Social networks based on semantic indexing of content allow the analysis of content systems, interactions and social representations based on micro conversations from a perspective of distributed production of identity expressions.

Age and gender categories correlate with differences in social power, status, and access to resources. In this sense, both categories fall into power relations systems that shape all other social hierarchies [10]. Richardson [11] argues that "gender is socially and spatially (re)created and (re)organised in different ways by different generations". An intergenerational approach to masculinities allows for an understanding of everyday practices over generations of men from an intersection perspective. Intergenerationality is one of the elements to consider in social relations given that "masculinities are formed relationally with and against femininities, but also with and against other masculinities" [11].

This article aims to explore how digital collective narratives represent masculinities, shedding light on intergenerational dynamics. The research question that guides this study is: How do digital collective narratives represent masculinities, and how do those representations reflect intergenerational identities and relations? How can digital collective narratives portray male intergenerational relations? To answer this question, we will analyse collective narratives on Instagram through a hashtag stream, focusing 
specifically on representations of masculinities and how different generations interact and represent how to be, behave and express as a man.

\subsection{Age and Gender: Intersecting Masculinities and Ageing}

Masculinity is usually understood as a set of features that characterise and provide guidance on how boys and men should be, express themselves and behave. Although there is a hegemonic understanding of masculinity, Connel sheds light on the need to acknowledge the existence of 'multiple masculinities' [4, 12], namely hegemonic, complicit, subordinate, and marginal or subaltern masculinities, which are structured in relation to a specific patriarchal gender hierarchy [13].

The concept of 'hegemonic masculinity' refers to specific attributes - e.g. rationality, toughness, leadership, strength - and cultural dynamics through which men claim and perpetuate a position of power in the existing gender hierarchy $[4,13]$. It is, thus, a normative proposal which represents an ideal to which men and boys should look up, offering guidance on how boys and men should be, think, feel, express themselves and behave [2, 3]. Men who adopt attributes commensurate with the ideal of hegemonic masculinity can assert their (alleged) superiority over women (and non-hegemonic men) and consolidate their general position of domination over them [14]. According to Connell [10], 'complicit masculinities' are characterized by an identification with the practices of hegemonic masculinity, seeking the benefits of the patriarchy [10]. Whereas "hegemonic masculinity" is not statistical, but rather normative $[2,4]$; complicit masculinities can become statistically prominent.

In turn, the notion of subaltern masculinity emerges from an unequal relationship that is established between hegemonic masculinities and those who do not conform to them $[15,16]$. In fact, "men who do not fit the paradigm of hegemonic masculinity and who show characteristics understood as "feminine" (e.g. sensitivity, fear, emotion, subordination, and passivity) are invariably ridiculed and viewed as inferior" [7, 14]. As Januário explains, the practices of subordination and domination include open and direct violence but also other less visible forms of violence, such as economic and social discrimination [16]. As masculinities and femininities are relational and defined on a binary basis, the "symbolic in subordinate masculinity approaches the symbolic of femininity" [17].

A growing body of literature has focused on 'toxic masculinities' [18] and 'hybrid masculinities' [19]. The concept of toxic masculinity depicts regressive male traits that fuel the need and legitimacy of (unjustified) violence and domination, subscribing not seldom times misogynist and homophobic ideologies [14, 18]. Finally, 'hybrid masculinities' can be defined as incorporation of identity elements that are associated with various marginalized and subordinated masculinities, as well as the performance of femininities and privileged male gender identities [19]. Bridges and Pascoe argue that "hybrid masculinities [which] may place discursive (though not meaningful) distance between certain groups of men and hegemonic masculinity, are often undertaken with an understanding of White, heterosexual masculinity as less meaningful than other (more marginalized or subordinated) forms of masculinity, and fortify social and symbolic boundaries and inequalities" [19]. 
The configurations of practices and behaviours are socially constructed [1] and therefore cannot be perceived and interpreted as static. The cultural diversity of the meanings of masculinity and femininity [17] is associated with a geographic diversity [19], as well as the idea that the practices and behaviours change as a function of space and time [10].

\subsection{Identities, Collective Narratives and Online Engagement}

Identity is the essence of being and ensures a sense of continuity in individuals, groups and society itself, even if in constant (re)construction [20]. It derives from the socialization process and summarizes existential pathways that are in permanent (re)adaptation and (re)invention, requiring thus (re)negotiation.

The Internet is often seen is a space for participatory and collective culture, identity formation in online environments is one of the central points of cyberculture research [20]. However, it can also be seen as a platform where the worst of offline is shared and represented. This comes as no surprise since the internet is a social network [21]. The social networking argument goes back to the idea of a networked society built on a fragmented collective identity that uses the network to bind to other subjects with similar attributes or preferences. Just like it happens offline, cyberspace is a repository of "narratives created by its inhabitants that remind us who we are, it is life as lived and reproduced in pixels and virtual texts" [22]. As such, for Turkle [23] "the Internet has become a significant social laboratory for (...) shap[ing] and creat[ing] ourselves". However, as Pierre Lévy [24] argues, it is important to demystify the theory that tends to see offline and online as opposites and not as interconnected realms. In fact, "real" and "virtual" are not antagonistic spaces but rather influence each other. Thus, the construction of online identity is influenced by elements that are external to the virtual realm and one may say imported from offline. On the other hand, the user experiences with the space of a given social network directly interfere with the construction of the self. Immersive experiences in virtual environments allow the user integration in space and the network, as a social sphere, actively, providing new relationships and social practices based on the premise of an integrated element in the community.

Contemporary socio-technical spheres are embodied in large-scale action networks and are becoming prominent in the various dimensions of society [20]. These networks enhance organised and institutionalised collective actions as a consequence of new modes of expression [25-27]. The digital age promotes individualised forms of individual and political action, challenging the nature of collective action [28]. 'Digital network action' depends on the intersection between personal action and social media networks [25].

Cyberspace enhances the shared social construction that materialises in platforms in which communication flows and debate is promoted, as Dahlberg [29] points out. Platforms such as Twitter, Instagram or Facebook are tools that support collective identity by facilitating communication channels.

Older people are not a homogeneous group that is isolated from the digital context [30-32]. Social representations anchored to the idea of old age, such as 'dependence' and 'useless', fill the social imaginary that the media perpetuate [3, 33]. However, digital platforms tend to bring generations together [34-36].

Collective narrative processes in digital enhance intergenerational relations. Content indexing is a digital practice with various appropriations. "The functional significance of 
hashtags resides in the archival cataloguing of topics and discussions generated by users which can underpin the emergence of social worlds and allow them to function in the new media environment" [37]. There is an individual culture of network participation, which is reflected in the sense of belonging, identity and group through code appropriation and semantic indexing [20]. Also, through a hashtag structure, online media are able to visibly aggregate individual testimonies and expressions into a networked collective narrative, allowing the dissemination [38] of specific understandings of particular identities, namely gender and age.

\section{Method}

This article aims to map and analyse the expression of an intergenerational masculinity identity in collective narratives, through content semantically indexed in the photosharing service Instagram. "How do digital collective narratives represent masculinities, and how do those representations reflect intergenerational identities and relations?" is the research question that guides this paper. The study relies on collective narrative processes around the hashtag \#fashiongrandpas, which we understand as one expression that aggregates intergenerational representations of masculinities.

Considering the assumption of media affordances [39] and "moulding forces" on social practices [40], computational methods were used to extract data within a mediumspecific approach [41]. The dataset was collected through the tool Instagram Scraper and consists of randomly selected 1068 media items published between 2011-12-18 and 2019-11-23. The time period of the sample comprehends the time span from the first time the hashtag has been used on Instagram until the day when the data was retrieved through Instagram Scraper. Data was collected from the public stream of Instagram by the semantic indexation to the hashtag. The media items are mostly photos $(n=1052$, $98.5 \%$ ). Video content published with the hashtag \#fashiongrandpas is only residual ( $\mathrm{n}$ $=16,1.5 \%)$.

The methodological approach is a quantitative content analysis to map the intergenerational male identity collective expressions. The main goals of this study are to 1). Identify the most common hashtags used with \#fashiongrandpas; 2). Map the dominant discourses about the hashtag in analysis; 3 ). Analyse most engaged media items correlating these with the dominant discourses.

\section{Results and Discussion}

The \#fashiongrandpas hashtag is mobilised in posts by people of various generations, predominantly among older adults and adults profiles about everyday life. In younger generations, the hashtag is used by profiles whose central topic is fashion. The use of the hashtag for several generations refers to the symbolic capital that \#fashiongrandpas entails as an umbrella for the identity expression of multiple masculinities. Most users identify themselves or can be identified as man.

The ten most common co-hashtags published between 2011-12-18 and 2019-11-23 are presented in Table 1. Hashtags are used to anchor content to collective narrative processes. The results show three predominant modes of appropriation of semantic 
indexing: 1). Indexing of fashion content; 2). Use of common hashtags on Instagram to index content to streamings with more users; 3 ). Including soft porn content by indexing the hashtag \#fashiongrandpas.

Table 1. Top 10 co-hashtags.

\begin{tabular}{l|l}
\hline Hashtags & Frequency \\
\hline \#style & 222 \\
\hline \#fashion & 216 \\
\hline \#menswear & 163 \\
\hline \#instadaily & 114 \\
\hline \#instamood & 108 \\
\hline \#followme & 107 \\
\hline \#samatized & 105 \\
\hline \#budapestsam & 104 \\
\hline \#nofilter & 103 \\
\hline \#lifeassam & 103 \\
\hline
\end{tabular}

The use of hashtags mobilises different types of social capital. Indexing content aggregates individuals into disaggregated streaming microstructures, enhancing the mobilisation of social capital distinctly from the macrostructures [20, 42]. Through content analysis, we have isolated five social practices [20] as described in Table 2.

Table 2. Social appropriations in the use of hashtags.

\begin{tabular}{l|l}
\hline Appropriation & Social practice \\
\hline Content publishing & $\begin{array}{l}\text { Content publishing; conversation through the publication of content; } \\
\text { posting content mentioning other users; content posting with mention of } \\
\text { the user himself/herself }\end{array}$ \\
\hline Conversation & $\begin{array}{l}\text { Conversation with other users by publishing content; posting content } \\
\text { mentioning other users; content with self-referencing }\end{array}$ \\
\hline Meta conversation & $\begin{array}{l}\text { Reproduction of content from other users; reproduction of content from } \\
\text { other users with mentioned sources; meta-conversation with content } \\
\text { added by the reproducing user; reproducing content from other users with } \\
\text { mentions of other actors }\end{array}$ \\
\hline Multiple indexing & $\begin{array}{l}\text { Posting content, conversation through content, or reproducing the content } \\
\text { that is indexed to more than one hashtag }\end{array}$ \\
\hline Self-refencing & $\begin{array}{l}\text { Posting content with self-references to the author; reproduction of user's } \\
\text { own content with his/her mention }\end{array}$ \\
\hline
\end{tabular}


Table 2 presents the sociability modalities observed, considering them as a result of an adaptation to the new spatiotemporal conditions. The observed practices refer to flows where information circulates, and social connections are established. Following Gurvitch [43], we consider that appropriations of media affordances and semantic indexing are embodied in spontaneous and organized sociability. We found that there are practices that translate the identification of users with the stream \#fashiongrandpas. The practices of self-referencing, multiple indexing, and isolated publication of non-interacting content all fit into organised sociability and are the most common. Conceptually, it is also possible to consider that social practices of content publishing, conversation and meta-conversation are forms of spontaneous sociability.

Social capital is directly related to the concept of network culture because it is established through social ties that bond individuals. Social capital is defined by Bourdieu [44] as being generated by social relations and requiring actors' effort for sociability and investment. Bravo and Bertolini [45] developed a multidimensional perspective based on five dimensions: 1). relational social capital (relationships that are established between individuals); 2). cognitive social capital (relationship with knowledge transmission and acquisition); 3). normative social capital (rules that must be followed by a particular social group); 4). social capital of trust in the social environment (the level of confidence that individuals accredit in a given social context); 5). institutional social capital (the institution in which the group is inserted).

In the context of self-interest theories [46], social capital stems from social dynamics that occur through the appropriation of platforms and their affordances. Recuero [42] states that the concept of social capital refers to the set of resources that exist in the relationships between individuals and that result from belonging to a system. Zago and Batista [47] argue that social capital is a central process and founder of the social dynamics, which result from social structures. Therefore, "cooperation between individuals makes possible not only the emergence of collective actions by generating social capital based on common interest and the pursuit of reputation but the emergence of life in society".

Adapting Bravo and Bertolini's proposal [45] to the instantaneity of the digital context, Table 3 presents a categorisation of appropriations of media's affordances and semantic indexing. These are concretised in social practices that result from sociability modalities and generate social capital. The social capital dimension of trust in the social environment was not operationalised. We consider that it was not possible to assess the mobilisation of this type of social capital without a qualitative content analysis.

Table 3. Social capital mobilised through the appropriations in the use of hashtags.

\begin{tabular}{l|l}
\hline Appropriation & Social capital \\
\hline Content publishing & Cognitive social capital \\
\hline Conversation & Relational social capital \\
\hline Meta conversation & Institutional social capital \\
\hline Multiple indexing & Normative social capital \\
\hline
\end{tabular}


The results show that the media items analysed include cognitive social capital (content publishing), relational social capital (conversation), institutional social capital (meta-conversations). We also consider that the use of multiple hashtags reveals the presence of normative social capital [47].

We identified 3500 hashtags used simultaneously with \#fashiongrandpas in the analysed posts, published between 2011-12-18 and 2019-11-23. Then we categorised those that appeared more than 50 times in the sample. This parameter resulted in a small dataset of 45 hashtags which we then further analysed and created ten categories of hashtags (Table 4).

Table 4. Categories of co-hashtags.

\begin{tabular}{|c|c|c|}
\hline Category & Hashtags & Use frequency \\
\hline Beauty & \#samtheagency $(n=77)$, \#handsome $(n=57)$ & 134 \\
\hline Fashion & $\begin{array}{l}\text { \#style }(n=222), \# \text { fashion }(n=216), \text { \#menswear } \\
(n=163), \text { \#swag }(n=100), \text { \#mensfashion }(n= \\
\text { 95), \#streetstyle }(n=83), \text { \#beardedmodel }(n= \\
\text { 78), \#streetfashion }(n=68) \text {, \#malemodel }(n=63) \text {, } \\
\text { \#streetwear }(n=57), \text { \#outfitoftheday }(n=51), \\
\text { \#menfashion }(n=50),\end{array}$ & 1246 \\
\hline Toxic masculinities & \#oldgoat $(n=85)$, \#realmen $(n=86)$ & 171 \\
\hline Hybrid masculinities & weeerk $(n=66)$ & 66 \\
\hline Instagram & $\begin{array}{l}\text { \#instadaily }(n=114) \text {, \#instamood }(n=108) \text {, } \\
\text { \#followme }(n=107) \text {, \#nofilter }(n=103) \text {, \#follow } \\
(n=101), \text { \#webstagram }(n=97), \text { \#instagood }(n= \\
\text { 87), \#inspiration }(n=63)\end{array}$ & 780 \\
\hline Hegemonic masculinities & $\begin{array}{l}\text { \#menstyle }(n=71) \text {, \#bearded }(n=69), \\
\text { \#beardedmen }(n=68) \text {, \#beardporn }(n=67), \\
\text { \#beardlife }(n=61) \text {, \#beard }(n=57) \text {, \#beards }(n= \\
\text { 56) }\end{array}$ & 449 \\
\hline Vintage style & \#crackedactor $(n=73)$, \#vintage $(n=52)$ & 125 \\
\hline Photo & $\begin{array}{l}\text { \#portrait }(n=71) \text {, \#streetphotography }(n=57) \text {, } \\
\text { \#ootd }(n=56) \text {, \#selfie }(n=51)\end{array}$ & 235 \\
\hline Places & \#nyc $(n=101)$ & 101 \\
\hline Soft-porn & $\begin{array}{l}\text { \#samatized }(n=105) \text {, \#budapestsam }(n=104), \\
\text { \#hegivesgoodface }(n=103) \text {, \#lifeassam }(n=103) \text {, } \\
\text { \#youwontforgetmyface }(n=91) \text {, \#hotdaddy }(n= \\
\text { 63), \#madeinhungary }(n=55)\end{array}$ & 624 \\
\hline
\end{tabular}

\#fashiongrandpas streaming is associated with fashion issues but also with an intergenerational approach to male identity. The categories of co-hashtags show that the dominant discourses are about fashion, soft-porn and hegemonic masculinities. Instagram, photo and places are instrumental categories in which hashtags are used to index 
the content to multiple streams. The sixth category corresponds to discourses on toxic masculinities. There is also the presence of discourses on hybrid masculinities, specifically transgender. The beauty and vintage categories are connected to fashion and can be assumed as sub-categories. In fact, the vintage category is associated with nostalgic publications, retrieving concepts of masculinity from the past and featuring replicas of the multiple and hybrid masculinities assumed by David Bowie.

The engagement with the content analysed through the indicator 'like' has an average of 256.81 likes per post, with a total of 274268 likes (Table 5).

Table 5. Number of likes (categorised into quartiles).

\begin{tabular}{l|r|r}
\hline Likes & \multicolumn{1}{l|}{$n$} & \multicolumn{1}{l}{$\%$} \\
\hline$<=50$ & 394 & 36.9 \\
\hline $51-100$ & 138 & 12.9 \\
\hline $100-150$ & 94 & 8.8 \\
\hline$>151$ & 442 & 41.4 \\
\hline Total & $\mathbf{1 0 6 8}$ & $\mathbf{1 0 0 . 0}$ \\
\hline
\end{tabular}

The engagement generated concerning the comment indicator is reduced. Most posts have less than five comments (58.2\%), and only $10.4 \%$ have more than 20 comments (Table 6).

Table 6. Comments on posts (categorised into quartiles).

\begin{tabular}{l|r|r}
\hline Comments & \multicolumn{1}{l|}{$n$} & \multicolumn{1}{l}{$\%$} \\
\hline$<=5$ & 625 & 58.5 \\
\hline $5-10$ & 179 & 16.8 \\
\hline $11-20$ & 153 & 14.3 \\
\hline$>21$ & 111 & 10.4 \\
\hline Total & $\mathbf{1 0 6 8}$ & $\mathbf{1 0 0 . 0}$ \\
\hline
\end{tabular}

Posts with greater engagement through 'likes' portray older men being the predominant descriptor is fashion (Table 7). The data show that intergenerational and crossgenerational content is the most prominent of the sample in terms of engagement. There is also a diversity of themes. 
Table 7. Hashtags in the captions of the top ten posts according to likes.

\begin{tabular}{l|l|l|l}
\hline Likes & Hashtags & Descriptor & Generation depicted \\
\hline 2299 & $\begin{array}{l}\text { \#relationshipgoals, \#levelten, \#stayfresh, } \\
\text { \#fashiongrandpas, \#notfashiondads, } \\
\text { \#originalhipsters, \#badassmc, \#love, } \\
\text { \#celebration }\end{array}$ & Love & Old adults \\
\hline 2156 & $\begin{array}{l}\text { \#preach, \#fashiongrandpas, } \\
\text { \#ifeellikeabadasstoday, \#thursdayrulez }\end{array}$ & Old age & Old adults \\
\hline 1900 & $\begin{array}{l}\text { \#halloween, \#fashiongrandpa, \#up!!, \#icant, } \\
\text { \#toomuchcute, \#littlebowtie, \#fashiongrandpas }\end{array}$ & Kids & Children \\
\hline 1594 & $\begin{array}{l}\text { \#waytogo, \#cuba, \#havana, \#local, \#localsonly, } \\
\text { \#fashiongrandpas, \#stunning, \#chipper, \#cigars, } \\
\text { \#gentleman, \#killingit, \#swagfordays }\end{array}$ & Fashion & Young old adults \\
\hline 1553 & $\begin{array}{l}\text { \#mondays, \#fashiongrandpas } \\
\text { \#vfashionshow, \#yeahright, \#fashiongrandpas, }\end{array}$ & Sport & Old adults \\
\hline 1543 & $\begin{array}{l}\text { \#bae, \#beardonfleek, \#fashiongrandpas, } \\
\text { \#hiphiphooray, \#complexgrandpas, } \\
\text { \#whoisthisman, \#letsgrabacoffee }\end{array}$ & Fashion & Young old adults \\
\hline 1499 & $\begin{array}{l}\text { \#fashiongrandpasstrong, \#fashiongrandpas, } \\
\text { \#backtoback, \#showsomelove, \#argyle, \#swag }\end{array}$ & Fashion & Old adults \\
\hline 1460 & $\begin{array}{l}\text { \#heartbreakers, } \\
\text { \#beyoncegotnothingonthesefashiongrandpas, } \\
\text { \#fashiongrandpas, \#runshit }\end{array}$ & Old age & Old adults \\
\hline \#fashiongrandpas & Family & Intergenerational \\
\hline
\end{tabular}

There are three matching posts in the top ten likes and comments that portray seniors and kids. Their descriptors are love, kids and sports. In the posts with the most comments (Table 8), there are three that ridicule senior citizens. These are young adult publications.

This study argues that content categorised as fashion, beauty, hegemonic masculinities, toxic masculinities, and hybrid masculinities is mostly cross-generational. Intersections between adults and old adults are common in discourses on hegemonic and toxic masculinities. The contents of the vintage category are markedly generational, published by young users. Men of different generations post soft-porn content. 
Table 8. Hashtags in the captions of the top ten posts according to comments.

\begin{tabular}{|c|c|c|c|}
\hline Comments & Hashtags & Descriptor & $\begin{array}{l}\text { Generation } \\
\text { depicted }\end{array}$ \\
\hline 217 & $\begin{array}{l}\text { \#relationshipgoals, \#levelten, \#stayfresh, } \\
\text { \#fashiongrandpas, \#notfashiondads, } \\
\text { \#originalhipsters, \#badassmc, \#love, \#celebration }\end{array}$ & Love & Old adults \\
\hline 191 & $\begin{array}{l}\text { \#plaid, \#sunny, \#florida, \#cool, \#learningthisdance, } \\
\text { \#swag, \#stepup, \#fashiongrandpas }\end{array}$ & Ridicule & Old adults \\
\hline 187 & $\begin{array}{l}\text { \#bae, \#beardonfleek, \#fashiongrandpas, } \\
\text { \#hiphiphooray, \#complexgrandpas, } \\
\text { \#whoisthisman, \#letsgrabacoffee }\end{array}$ & Fashion & $\begin{array}{l}\text { Young old } \\
\text { adults }\end{array}$ \\
\hline 153 & $\begin{array}{l}\text { \#preach, \#fashiongrandpas, } \\
\text { \#ifeellikeabadasstoday, \#thursdayrulez }\end{array}$ & Older people & Old adults \\
\hline 153 & $\begin{array}{l}\text { \#halloween, \#fashiongrandpa, \#up!!, \#icant, } \\
\text { \#toomuchcute, \#littlebowtie, \#fashiongrandpas }\end{array}$ & Kids & Children \\
\hline 119 & $\begin{array}{l}\text { \#vsfashionshow, \#yeahright, \#fashiongrandpas, } \\
\text { \#repost }\end{array}$ & Sport & Old adults \\
\hline 111 & $\begin{array}{l}\text { \#fashiongrandpas, \#onedayonly, } \\
\text { \#unlessyoureafashiongrandpa, \#merightnow, } \\
\text { \#squeeze, \#relationshipgoals, \#relationshipreality, } \\
\text { \#meandbae, \#truelove }\end{array}$ & Manhood & Old adults \\
\hline 108 & $\begin{array}{l}\text { \#fashiongrandpas, \#applause, \#legend, } \\
\text { \#mrjehovas, \#legendseverywhere, \#boombox, } \\
\text { \#nothomeless, \#justfeelslikeit, \#highkick, } \\
\text { \#societycantkeepup }\end{array}$ & Performance & Old adults \\
\hline 104 & $\begin{array}{l}\text { \#heartbreakers, \#repost, \#amiright, } \\
\text { \#fashiongrandpa, \#fashiongrandpas, \#elite, } \\
\text { \#wewelcomeyou }\end{array}$ & Ridicule & Old adults \\
\hline 99 & $\begin{array}{l}\text { \#tokyo, \#fashiongrandpas, \#fur, \#red, \#boss, } \\
\text { \#plaid, \#dukeoftokyo, \#prancing, \#og, } \\
\text { \#pimpdaddy, \#myspiritanimal, \#trustnobitch, } \\
\text { \#getoutofthewaybasics }\end{array}$ & Ridicule & Old adults \\
\hline
\end{tabular}

\section{Conclusions and Limitations}

This paper aimed to analyse the expression of an intergenerational male identity in collective narratives, in order to answer the research question: "How do digital collective narratives represent masculinities, and how do those representations reflect intergenerational identities and relations?".

The analysis shows that online representations of male identities tend to perpetuate hegemonic masculinity. Therefore, power relations are perpetuated in images that anchor discourses of heteronormativity that tend to confirm a man's ideal. How men should be and behave is presented as an aggregating element of male group identity. Fashion, 
beauty, manhood and soft-porn as aggregating elements, the expressions of being a man are shared in the analysed stream. The complexity and multiplicity of masculinities arise in dissonant discourses as they are not consistent with a single identity. Hybrid masculinities exist in the stream because they share the aggregating hashtag but mobilise different ideas and concepts from being a man.

Multiple masculinities are present in the sample analysed. From an intergenerational perspective and with a unique group identity, hashtags are mobilised to create identity ties that derive from different types of social capital [45].

Considering that masculinities form relationally with and against femininities as well as with and against other masculinities [11], we found differences in the appropriation of the hashtag for different purposes. There are traces of hegemonic masculinities in power relations, especially ridiculing old adults as opposed to strong young men. It is also verified that hybrid masculinities assume an intersectional character, considering class and race. However, this issue is not considered in the discourses that fall into the other categories.

Given that the use of a hashtag is a form of content indexing and thus a statement, we consider that the 1068 posts analysed are 'digital network action' [25] that promote ideologies in collective narrative processes. With traits of hegemonic masculinity but also common of manhood, the men portrayed in the contents of this streaming refers to the ideal of group identity. The fashion and beauty discourses emphasise a collective identity: white, heterosexual and financially healthy man.

The main limitations of this study are related to the quantitative approach. Future research will focus on qualitative content analysis of posts and comments, as well as analysis of post-tag and co-tag networks.

\section{Implications for Future Studies}

The results of this study show that the dominant masculinity discourses on Instagram perpetuate hegemonic masculinities anchored upon heteronormativity. However, we note that there is no single intergenerational male identity. The results shed light on the complexity of 'multiple masculinities' $[4,12]$ in the collective process of narratives analysed. Hegemonic masculinities, toxic masculinities, and hybrid masculinities are cross-generational. Future studies should take the theory of intersectionality as a theoretical framework and consider mixed methodologies furthering qualitative analysis to complement the quantitative perspective.

Moreover, future studies on digital collective narratives of masculinity should endeavour to identify whether the data reveals a connective action logic [25] by analysing co-hashtag networks from a cross-platform perspective [48]. Hashtag co-occurrence networks enable to observe indirect connections in order to explore associations, related actors and content (visual and textual). Furthermore, it is possible to identify if there are intersections between masculinity discourses on different platforms, promoted by connective actions. This methodological approach also makes it possible to identify the dominant voices, central actors, network patterns, community building, as well as the discourses mobilised as ties between communities. 
Acknowledgments. This article was financed by national Portuguese funds through FCT (Fundação para a Ciência e a Tecnologia) in the framework of the project "(De)Coding Masculinities: Towards an enhanced understanding of media's role in shaping perceptions of masculinities in Portugal" (Reference PTDC/COM-CSS/31740/2017).

\section{References}

1. Lorber, J., Farrell, S.A.: The Social Construction of Gender. Sage, Newbury Park (1991)

2. Connell, R.W., Messerschmidt, J.W.: Hegemonic masculinity: rethinking the concept. Gender Soc. 19(6), 829-859 (2005)

3. Amaral, I., Santos, S.J., Daniel, F., Filipe, F.: (In)visibilities of men and aging in the media: discourses from Germany and Portugal. In: Zhou, J., Salvendy, G. (eds.) HCII 2019. LNCS, vol. 11593, pp. 20-32. Springer, Cham (2019). https://doi.org/10.1007/978-3-030-22015-0_2

4. Carrigan, T., Connell, B., Lee, J.: Toward a new sociology of masculinity. Theory Soc. 14(5), 551-604 (1985)

5. Mannheim, K.: The problem of generation. In: Mannheim, K. (ed.) Essays on the Sociology of Knowledge, pp. 276-320. Routledge \& Kegan Pau, London (1952)

6. Corsten, M.: The time of generations. Time Soc. 8(2-3), 249-272 (1999)

7. Boni, F.: Framing media masculinities: men's lifestyle magazines and the biopolitics of the male body. Eur. J. Commun. 17(4), 465-478 (2002)

8. Katz, J., Earp, J.: Tough Guise: Violence, Media \& the Crisis in Masculinity. Media Education Foundation (1999)

9. Colombo, F., Fortunati, F.: Broadband Society and Generational Changes. Peter Lang, Frankfurt am Main (2011)

10. Connell, R.W.: Masculinities, 2nd edn. University of California Press, Berkeley (2005)

11. Richardson, M.J.: Embodied intergenerationality: family position, place and masculinity. Gender Place Cult. 22(2), 157-171 (2015)

12. Connell, R.W.: Masculinities. University of California Press, Berkeley (1995)

13. Hopkins, P., Noble, G.: Masculinities in place: situated identities, relations and intersectionality. Soc. Cult. Geogr. 10(8), 811-819 (2009)

14. Santos, S.J.: Entre o papel de espelho e o de produtor da realidade: os media e a (des) codificação de masculinidades. In: Atas do Seminário Internacional "Media e violência sexual: da investigação à comunicação", pp. 139-158. CES, Coimbra (2018)

15. Kimmel, M.S.: A produção simultânea de masculinidades hegemônicas e subalternas. Horizontes Antropológicos 4(9), 103-117 (1998)

16. Januário, S.B.: Masculinidades em (re) construção: Gênero, Corpo e Publicidade. LabCom. IFP, Covilhã (2016)

17. Gardiner, J.K.: Masculinity Studies and Feminist Theory. Columbia University Press, New York (2002)

18. Kupers, T.A.: Toxic masculinity as a barrier to mental health treatment in prison. J. Clin. Psychol. 61(6), 713-724 (2005)

19. Bridges, T., Pascoe, C.J.: Hybrid masculinities: new directions in the sociology of men and masculinities. Sociol. Compass 8(3), 246-258 (2014)

20. Amaral, I.: Redes Sociais na Internet: Sociabilidades Emergentes. LabCom Books, Covilhã (2015)

21. Cavanagh, A.: Sociology in the Age of the Internet. Tata McGraw-Hill Education, New York (2010)

22. Fernback, J.: The individual within the collective: virtual ideology and the realization of collective principles. In: Jones, S. (ed.) Virtual Culture: Identity \& Communication in Cybersociety, pp. 36-54. Sage Publications, London, Thousand Oaks, New Delhi (1997) 
23. Turkle, S.: A vida no ecrã. A identidade na era da Internet. Relógio d'Água, Lisboa (1997)

24. Lévy, P.: O que é o virtual. Quarteto Editora, Coimbra (2001)

25. Bennett, W.L., Segerberg, A.: The logic of connective action: digital media and the personalization of contentious politics. Inf. Commun. Soc. 15(5), 739-768 (2012)

26. Murru, M.F., Amaral, I., Brites, M.J., Seddighi, G.: Bridging the gap between micro and macro forms of engagement: three emerging trends in research on audience participation. In: Das, R., Ytre-Arne, B. (eds.) The Future of Audiences, pp. 161-177. Springer, Cham (2018). https://doi.org/10.1007/978-3-319-75638-7_9

27. Kavada, A.: Social movements and political agency in the digital age: a communication approach. Media Commun. 4(4), 8-12 (2016)

28. Bimber, B.: Three prompts for collective action in the context of digital media. Political Commun. 34(1), 6-20 (2017)

29. Dahlberg, L.: Democracy via cyberspace: mapping the rhetorics and practices of three prominent camps. New Media Soc. 3(2), 157-177 (2001)

30. Amaral, I.: Senior citizens and the internet. In: Merskin, D. (ed.) The SAGE International Encyclopedia of Mass Media and Society, pp. 1549-1551. Sage Publications, Thousand Oaks (2020)

31. Loos, E.: Generational use of new media and the (ir)relevance of age. In: Colombo, F., Fortunati, L. (eds.) Broadband Society and Generational Changes, pp. 259-273. Peter Lang, Berlin (2011)

32. Loos, E.: Senior citizens: digital immigrants in their own country? Observatorio (OBS*) 6(1), 01-023 (2012)

33. Daniel, F., Antunes, A., Amaral, I.: Representações sociais da velhice. Análise Psicológica 33(3), 291-301 (2015)

34. Bolin, G., Skogerb $\varnothing$, E.: Age, generation and the media. Northern Lights 11, 3-14 (2013)

35. Amaral, I., Brites, M.J.: Trends on the digital uses and generations. In: Proceedings of INTED2019 Conference, INTED, Valencia, pp. 5109-5115 (2019)

36. Loos, E., Haddon, L., Mante-Meijer, E.: Generational Use of New Media. Routledge, London and New York (2016)

37. Lamont, M., Ross, A.S.: Deconstructing embedded meaning within cyclists' Instagram discourse: \#fromwhereiride. Ann. Leis. Res. 1-25 (2019)

38. Clark-Parsons, R.: "I SEE YOU, I BELIEVE YOU, I STAND WITH YOU": \#MeToo and the performance of networked feminist visibility. Feminist Media Stud. 1-19 (2019)

39. Bucher, T., Helmond, A.: The affordances of social media platforms. In: The SAGE Handbook of Social Media, pp. 223-253 (2017)

40. Hepp, A.: Cultures of Mediatization. Wiley, Hoboken (2013)

41. Rogers, R.: Digital Methods. MIT Press, Cambridge (2013)

42. Recuero, R.: Redes sociais na internet. Sulina, Porto Alegre (2009)

43. Gurvitch, G.: A vocação actual da Sociologia. Cosmos, Lisboa (1986)

44. Bourdieu, P.: O poder simbólico. Difel, Lisboa (2001)

45. Bertolini, S., Bravo, G.: Social Capital, a Multidimensional Concept (2004). https://pdfs.sem anticscholar.org/ab8d/2ed286d0c225b47fca4785cef2dd1dc7fac6.pdf. Accessed 16 Dec 2019

46. Monge, P., Contractor, N.: Emergence of communication networks. In: Jablin, F., Putnam, L. (eds.) Handbook of Organizational Communication, pp. 440-502. Sage, Thousand Oaks (1999)

47. Zago, G., Batista, J.: Manifestações coletivas no ciberespaço: cooperação, capital social e redes sociais. In: Actas do Simpósio Nacional da ABCIBER, São Paulo, vol. 1 (2008)

48. Omena, J.J., Amaral, I.: Sistema de leitura de redes digitais multiplataforma. In: Omena, J.J. (ed.) Métodos Digitais: Teoria-Prática-Crítica, pp. 121-140. iNOVA Media Lab - ICNOVA, Lisboa (2019) 